LBL -36782

UC - 426

\title{
SURFACE MODIFICATION OF NICKEL BATTERY ELECTRODES BY COBALT PLASMA IMMERSION ION IMPLANTATION AND DEPOSITION
}

S. Anders, A. Anders, I. Brown, F. Kong, and F. McLarnon

Lawrence Berkeley Laboratory, University of California, Berkeley, CA 94720, USA

This work was supported by the Electric Power Research Institute under Award Number 8042-03 and the U.S. Department of Energy under Contract Number DE-AC037.6SF00098. 


\section{DISCLAIMER}

This report was prepared as an account of work sponsored by an agency of the United States Government. Neither the United States Government nor any agency thereof, nor any of their employees, make any warranty, express or implied, or assumes any legal liability or responsibility for the accuracy, completeness, or usefulness of any information, apparatus, product, or process disclosed, or represents that its use would not infringe privately owned rights. Reference herein to any specific commercial product, process, or service by trade name, trademark, manufacturer, or otherwise does not necessarily constitute or imply its endorsement, recommendation, or favoring by the United States Government or any agency thereof. The views and opinions of authors expressed herein do not necessarily state or reflect those of the United States Government or any agency thereof. 


\section{DISCLAIMER}

Portions of this document may be illegible in electronic image products. Images are produced from the best available original document. 


\title{
SURFACE MODIFICATION OF NICKEL BATTERY ELECTRODES BY COBALT PLASMA IMMERSION ION IMPLANTATION AND DEPOSITION
}

\author{
S. Anders, A. Anders, I. Brown, F. Kong, and F. McLarnon \\ Lawrence Berkeley Laboratory, University of California, Berkeley, CA 94720, USA
}

\begin{abstract}
Nickel hydroxide is the electrochemically active material in the positive electrode of several important rechargeable alkaline-electrolyte batteries. It is believed that divalent $\mathrm{Ni}(\mathrm{OH})_{2}$ is converted to trivalent $\mathrm{NiOOH}$ as the electrode is electrochemically oxidized during the battery charging process, and the reverse reaction (electrochemical reduction) occurs during battery discharge, however the details of this process are not completely understood. Because these electrochemical reactions involve surface charge-transfer processes, it is anticipated that surface modification may result in improved battery performance. We used broad-beam metal ion implantation and the new technique of Metal Plasma Immersion Ion Implantation and Deposition (MePIID) to add cobalt and other species to the nickel electrode surface. The principle of the latter technique is explained in detail. It is shown that implanted and deposited cobalt ions act as a dopant of $\mathrm{Ni}(\mathrm{OH})_{2}$, and thereby alter its electronic conductivity. This electronic effect promotes lateral growth of NiOOH nodules and more-complete conversion of $\mathrm{Ni}(\mathrm{OH})_{2}$ to $\mathrm{NiOOH}$, which can be interpreted in terms of the nodule growth model. Other dopants such as $\mathrm{Au}, \mathrm{W}, \mathrm{Pb}, \mathrm{Ta}$ and $\mathrm{Ti}_{4} \mathrm{O}_{7}$ were also tested for suppressing the parasitic oxygen evolution reaction in rechargeable nickel cells.
\end{abstract}




\section{Introduction}

The operation of rechargeable nickel batteries is based on the oxidation and reduction of the positive nickel electrode in alkaline electrolyte such as $\mathrm{NaOH}$; this is commonly written as the transformation between divalent nickel hydroxide, $\mathrm{Ni}(\mathrm{OH})_{2}$, and trivalent nickel oxy-hydroxide, NiOOH. When the battery is charged, the surface layer of $\mathrm{Ni}(\mathrm{OH})_{2}$ is partially oxidized to $\mathrm{NiOOH}$ and vice versa: when the battery is discharged, $\mathrm{NiOOH}$ is reduced to $\mathrm{Ni}(\mathrm{OH})_{2}$. This is, of course, a simplified picture because other processes occur and only a fraction of the $\mathrm{Ni}(\mathrm{OH})_{2}$ layer is converted. It is important to note that the interconversion works on electrode surfaces including the near surface layer. This suggests that surface modification techniques such as ion implantation and thin film deposition should be suitable tools to engineer optimum performance by tailoring electrode surface composition and structure.

In this paper we describe the surface modification of nickel electrodes by metal ion implantation and deposition. Emphasis is put on the effect of cobalt ions implanted and deposited by a novel surface modification technique called Metal Plasma Immersion Ion Implantation and Deposition (MePIIID). Other modification techniques such as conventional metal ion implantation are also discussed.

\section{Some Basics of Nickel Electrode Batteries}

The electrochemical interconversion $\mathrm{Ni}(\mathrm{OH})_{2} \Leftrightarrow \mathrm{NiOOH}+\mathrm{H}^{+}+\mathrm{e}^{-}$does not proceed in a uniform manner over the electrode surface. It is instead better described by the so-called nodular growth model [1]. When an anodic current is passing through the electrode, small nuclei of $\mathrm{NiOOH}$ form at the interface between the nickel electrode and the $\mathrm{Ni}(\mathrm{OH})_{2}$ film (Fig. 1) as the $\mathrm{Ni}(\mathrm{OH})_{2}$ is electrochemically oxidized. (The term "anodic" 
refers to the oxidation process, and "cathodic" to the reduction process, however the terms "anode" and "cathode" are ambiguous when applied to rechargeable battery electrodes because either anodic or cathodic processes can occur, depending on whether the battery is being charged or discharged). Because the electronic conductivity of $\mathrm{NiOOH}$ is much greater than that of $\mathrm{Ni}(\mathrm{OH})_{2}$, the current is concentrated where $\mathrm{NiOOH}$ nuclei grow and form nodules. The current density at the tips of the nodules is much greater than on their base, and thus the nodules grow mainly one-dimensional through the $\mathrm{Ni}(\mathrm{OH})_{2}$ film towards the electrolyte. The eventual exposure of the electronically conductive $\mathrm{NiOOH}$ to the electrolyte facilitates a competing Faradaic reaction: undesired oxygen evolution. Further conversion of $\mathrm{Ni}(\mathrm{OH})_{2}$ is thereby inhibited, leaving pockets of uncharged material trapped within the film.

The electrochemical behavior of nickel electrodes can be characterized by in-situ spectroscopic ellipsometry, even the electrode is polarized anodically or cathodically. Details of the self-scanning and self-nulling ellipsometer can be found in [2]. Information on the microstructural transformation happening on the electrode surface during the charge and discharge process can be gained from the observed ellipsometric spectra based on the large difference in the dispersive properties of $\mathrm{Ni}(\mathrm{OH})_{2}$ and $\mathrm{NiOOH}$. For instance, the hydroxide is weakly absorbing and nearly transparent in the visible whereas the oxyhydroxide is strongly absorbing in this region. The ellipsometer raw data are computed using the effective medium approximation containing the Fresnel equations and the Drude equation for a multiple layer structure [3]. As a result one obtains the volume fraction of $\mathrm{NiOOH}$ in the $\mathrm{Ni}(\mathrm{OH})_{2}$ film.

The goal of surface modification is to increase the fraction of interconversion and to suppress oxygen evolution. To achieve this goal, both metal ion implantation and MePIIID have been used. Since "conventional" metal ion implantation has been known for many years [4], we consider it only briefly and focus here on the new technique of MePIID. 


\section{Metal Plasma Immersion Ion Implantation and Deposition (MePIID)}

In conventional ion (beam) implantation, ions formed in a plasma are accelerated in a system of high voltage electrodes, and their kinetic energy is determined by the extraction voltage times the ion charge. The vacuum arc ion source is a special form of an ion source which is based on a vacuum arc discharge between electrodes in vacuum [5]. The cathode material is transformed into a fully ionized plasma at micron-size hot spots on the cathode surface. These cathode spots are locations of very high current density $\left(10^{11}-10^{12} \mathrm{~A} / \mathrm{m}^{2}\right.$ ), plasma density (greater than $10^{26} \mathrm{~m}^{-3}$ ) and temperature (about $50,000 \mathrm{~K}$ or $5 \mathrm{eV}$ ), see [5-7]. As a result, the vacuum arc plasma is not only fully ionized but contains even multiply charged ions [4].

An alternative way of doing ion implantation was developed by Conrad and coworkers [8]. Their technique of Plasma Source Ion Implantation (PSII), sometimes also called Plasma Immersion Ion Implantation (PIII), is based on the acceleration of ions in an electric sheath which forms around a conductive substrate when immersed in a gaseous plasma. The voltage drop in the sheath is periodically increased to very high negative values (many kilovolts or tens of kilovolts) so that ions gain $\mathrm{keV}$ or tens of $\mathrm{keV}$ energy. The bias is applied in a pulsed mode to avoid arcing and also to let the near-substrate plasma recover after a large amount of ions has been drained. Plasma densities are usually low (of order $10^{16} \mathrm{~m}^{-3}$ ), pulse durations are typically $10-100 \mu \mathrm{s}$, and the pulse duty cycle is usually not greater than a few percent [9]. PIII is a non-line-of-sight technique as long as the plasma sheath thickness is not much greater than the geometrical features of the substrate, i.e. all sides of the substrate are implanted at once without substrate manipulation.

A qualitatively different surface modification technique results if a condensable plasma (metal or carbon) is used since ions are not only implanted into but also deposited onto the substrate [10]. This technique is characterized by two phases: a high-energy ion 
implantation phase corresponding to the duration of the high voltage bias pulse, and a lowenergy ion deposition phase corresponding to the time between two bias pulses. Therefore, derived from PIII, this technique is called MePIIID (metal plasma immersion ion implantation and deposition).

\section{MePIIID using vacuum arc plasmas}

A very efficient way of producing large amounts of metal or carbon plasma is to use a vacuum arc (sometimes also called "cathodic arcs" since plasma formation happens in cathode spots). In contrast to vacuum arc ion sources, no ion extraction system is present, and therefore ions and electrons stream with the same macroscopic velocity (of order $10^{4} \mathrm{~m} / \mathrm{s}$ ) from the cathode spots into the vacuum ambient. Since the plasma expands from a region of high pressure, its density decreases with increasing distance from the spots. By choosing a suitable cathode-to-substrate distance the plasma density can be conveniently tuned. Other parameters which can be chosen are the arc current amplitude and duration. Thus, depending on the application, vacuum arc plasma sources can be matched to specific requirements.

Vacuum arc cathode spots produce not only plasma but also micron-size droplets (or solid debris in case of a graphite cathode). They are called "macroparticles" to emphasize their massive nature in contrast to individual plasma ions. A lot of work has been done to remove macroparticles from the vacuum arc plasma, and the most successful approach is separating them from the plasma by curved magnetic filters [11, 12]. The idea is to magnetize electrons (their motion is bound to magnetic field lines) and guide ions by the electric field which occurs when ions start to separate from the plasma electrons. In this way, both electrons and ions (i.e., the plasma as a whole) follow the magnetic field lines of the curved filter. Macroparticles, in contrast, move along almost straight paths due to their 
inertia; they hit the filter wall and stick there. Additional measures such as baffles are necessary to prevent macroparticle reflection from filter walls.

\section{Surface modification of nickel battery electrodes}

The surface of nickel electrodes was modified by two processes: (i) ion implantation using a vacuum arc ion source, and (ii) MePIID using a magnetically filtered vacuum arc plasma. In both cases, cobalt was used as the cathode material resulting in a cobalt ion beam and cobalt plasma flow, respectively. For comparison purposes, other materials such as copper were also used.

Nickel electrodes were mounted on a holder and inserted in the vacuum chamber of LBL's broad beam vacuum arc ion source. Experiments were performed with doses in the range between $3 \times 10^{15}$ ions $/ \mathrm{cm}^{2}$ and $7 \times 10^{16}$ ions $/ \mathrm{cm}^{2}$. The ion energy was kept constant at $50 \mathrm{keV}$. The pulsed ion beam current density at the target (nickel electrodes) was $7 \mathrm{~mA} / \mathrm{cm}^{2}$ with a duration of $250 \mu \mathrm{s}$ per pulse. High energy ion implantation results in a relatively deep implantation profile (Fig. 2). The Monte Carlo Code used for the simulation was T-DYN 4.0 (ref. [13]).

For MePIIID, cobalt plasma was produced by a pulsed vacuum arc plasma source with an arc current of $200 \mathrm{~A}$, arc duration $1 \mathrm{~ms}$, and a repetition rate of $5 \mathrm{~Hz}$. The plasma was magnetically filtered to obtain a macroparticle-free plasma. The nickel electrodes were placed about $10 \mathrm{~cm}$ from the filter exit. Bias pulses were generated by a high power pulse generator (maximum voltage $-2.2 \mathrm{kV}$, duration of each pulse $5 \mu \mathrm{s}$, duty cycle up to $50 \%$ ). Since the mean charge state of the cobalt ions was about 1.7 , the mean ion energy was about $3.8 \mathrm{keV}$ after acceleration in the electric sheath surrounding the nickel electrodes. The total cobalt dose (including deposition phase) was approximately $2 \times 10^{16}$ ions $/ \mathrm{cm}^{2}$. 
The experimental set-up for MePIID using a filtered vacuum arc plasma source is shown in Fig. 3.

Unmodified and modified nickel electrodes were investigated using ellipsometry. Fig. 4 shows the volume fraction of $\mathrm{NiOOH}$ obtained when a constant current density of $5 \mu \mathrm{A} / \mathrm{cm}^{2}$ is passed anodically. As expected, the volume fraction of $\mathrm{NiOOH}$ increases rapidly at the beginning of the charging process, and reaches a saturated value less than one. The experiments show that electrodes with cobalt ion implantation can reach a higher volume fraction of $\mathrm{NiOOH}$, in comparison with unmodified electrodes. The electrode with copper implantation, in contrast, shows the opposite effect. This can be attributed to the doping effect of foreign additives: cobalt additive balances to some extent the usually rather different conductivities of $\mathrm{Ni}(\mathrm{OH})_{2}$ and $\mathrm{NiOOH}$, and copper additive enhances the difference. Our experiments indicate that an increased conductivity of $\mathrm{Ni}(\mathrm{OH})_{2}$ reduces the current concentration in $\mathrm{NiOOH}$ nuclei and associated one-dimensional growth through the $\mathrm{Ni}(\mathrm{OH})_{2}$ film. Growth of $\mathrm{NiOOH}$ along the film plane makes the interconversion more complete and represents a beneficial effect of our modification techniques.

For comparison, cyclic voltammetry measurements have been done not only with unmodified and modified nickel electrodes but also with pure cobalt electrodes. They correspond to electrodes treated by MePIIID with negligible bias duty cycle (i.e., pure cobalt deposition without implantation). The result is shown in Figure 5. The disappearance of current peaks reveals that once cobalt atoms have been oxidized into a higher valence state, they cannot easily be reduced even when a polarization potential is applied cathodically.

Because the ellipsometric characterization is sensitive to the region close to the surface of the specimen, the relatively shallow depth profiles of MePIIID cobalt additives provides a good opportunity to study the electrochemical behavior of foreign additives. With the given range of MePIID bias potential and duty cycle, the ion penetration depth was about 2-3 nm, as shown in Fig. 6. By comparing model calculations to observed ellipsometric 
spectra, we conclude that the surface layer can be treated as a mixture of $\mathrm{Ni}(\mathrm{OH})_{2}, \mathrm{NiOOH}$ and foreign additives. During the charge and discharge of the electrode, the changes of the volume fractions of $\mathrm{Ni}(\mathrm{OH})_{2}$ and $\mathrm{NiOOH}$ are as expected. These conclusions agree with the cyclic voltammetry observation of a pure cobalt electrode, and exclude the possibility that the cobalt additives are directly involved in the electrochemical reactions happening at the electrode during the charge and discharge processes.

Because the oxygen evolution reaction at the nickel electrode surface strongly competes with the interconversion between $\mathrm{Ni}(\mathrm{OH})_{2}$ and $\mathrm{NiOOH}$ or other higher-valent nickel oxidation states, suppression of this unwanted parasitic reaction may lead to improved coulomb efficiency, energy efficiency and specific energy of electrochemical cells utilizing nickel electrodes. MePIID also provides a powerful tool to study the effects of varying the nickel electrode surface composition on the suppression of oxygen evolution. $\mathrm{Au}, \mathrm{Pb}, \mathrm{Ta}, \mathrm{Ti}, \mathrm{W}$ and $\mathrm{Ti}_{4} \mathrm{O}_{7}$ were chosen as dopants because of their relatively poor surface catalytic behavior with respect to oxygen evolution. (Note that not only pure metallic elements but also compound such as oxides can be formed by running the cathodic-arc plasma source in a gaseous environment.) The effects of these species on interconversion in nickel electrodes has not been well studied yet. The dose was approximately in the range between $4 \times 10^{15}$ and $2 \times 10^{16}$ ions $/ \mathrm{cm}^{2}$. This implies that the atomic fraction of foreign atoms at the electrode surface is of order $30 \%$. Preliminary tests showed that the overpotential for oxygen evolution at the surface of a $\mathrm{Ti}_{4} \mathrm{O}_{7}$-modified nickel electrode is increased by $50-105 \mathrm{mV}$, compared with electrodes implanted with other elements. Unfortunately, the suppression of oxygen evolution did not result in a better electrode performance. Among the doping materials investigated so far, $\mathrm{Au}, \mathrm{W}$, and $\mathrm{Pb}$ performed best with respect to the overall charge/discharge characteristics. However, the charge efficiency with these materials is significantly lower than the effect obtained by high-energy cobalt ion implantation. This fact suggests that the porosity of nickel battery 
electrodes may play an important role in the interconversion reactions, and high-energy ion implantation is best suited to improve battery performance.

\section{Conclusions}

MePIIID has been shown to be a superb tool for studying the role of additives in the interconversion of between $\mathrm{Ni}(\mathrm{OH})_{2}$ and $\mathrm{NiOOH}$. As anticipated, doping of nickel electrodes with cobalt resulted in increased interconversion and related improved coulombic efficiency. Other materials such as $\mathrm{Au}, \mathrm{W}$, and $\mathrm{Pb}$ showed a beneficial effect as well. Deep implantation, however, is required for porous nickel electrodes, and thus broad beam, high-energy ion implantation appears to be more appropriate than MePIII due to the higher ion energies available.

\section{Acknowledgments}

This work was supported by the Electric Power Research Institute under Award Number 8042-03 and the U.S. Department of Energy under Contract Number DE-AC03$76 S F 00098$. 


\section{References}

[1] R. W. Crocker and R. H. Muller, Structural Transformation of Nickel Hydroxide Films during Anodic Oxidation, Preprint LBL-32136 of Lawrence Berkeley Laboratory, May 1992.

[2] R. H. Muller, Rev. Sci. Instrum. 55 (1984) 371-374.

[3] R. H. Muller, Ellipsometry as an In Situ Probe for the Study of Electrode Processes, in: Techniques for Characterization of Electrodes and Electrochemical Processes, ed. by R. Varma and J. R. Selman, Wiley, New York, 1991, pp. 31-125.

[4] I. G. Brown, Rev. Sci. Instrum. 65 (1994) 3061-3081.

[5] B. Jüttner, IEEE Trans. Plasma Sci. 15 (1987) 474-480.

[6] A. Anders, S. Anders, B. Jüttner, W. Bötticher, H. Lück, and G. Schröder, IEEE Trans. Plasma Sci. 20 (1992) 466-472.

[7] A. Anders, S. Anders, A. Förster, and I. G. Brown, Plasma Sources Sci. Technol. 1 (1992) 263-270.

[8] J. R. Conrad, J. L. Radtke, R. A. Dodd, F. J. Worzala, and N. C. Tran, J. Appl. Phys. 62 (1987) 4591-4596.

[9] Papers in: Proceedings of First International Workshop on Plasma-Based Ion Implantation, published in J. Vac. Sci. Technol. B12, no. 2 (1994).

[10] A. Anders, S. Anders, I. G. Brown, M. R. Dickinson, and R. A. MacGill, J. Vac. Sci. Technol. B12 (1994) 815-820.

[11] I. I. Aksenov, V. A. Belous, V. G. Padalka, and V. M. Khoroshikh, Fiz. Plazmy 4 (1978) 758-763; Sov. J. Plasma Phys. 4 (1978) 425-428.

[12] A. Anders, S. Anders, and I. G. Brown, Plasma Sources Sci. Technol. 4 (1995) accepted for publication.

[13] J. P. Biersack, S. Berg, and C. Nender, Nucl. Instrum. Methods in Phys. Res. B56/60 (1991) 21-27. 


\section{Figure Captions}

Fig. 1 Nodular growth model (adapted from [1]); (a) before growth, (b) during growth of $\mathrm{NiOOH}$ nuclei and formation of nodules, (c) nodules growth is completed and oxygen evolution has started.

Fig. 2 Cobalt depth profile for cobalt ion implantation into nickel electrodes (Monte Carlo simulation with applied dose of $7 \times 10^{16}$ ions $/ \mathrm{cm}^{2}$ and ion energy $50 \mathrm{keV}$ ).

Fig. 3 Experimental arrangement for MePIIID of nickel electrodes with filtered metal plasma from a vacuum arc plasma source.

Fig. 4 Volume fraction of $\mathrm{NiOOH}$ as measured during charging $\left(5 \mu \mathrm{A} / \mathrm{cm}^{2}\right)$ for unmodified, Co-doped and $\mathrm{Cu}$-doped nickel electrodes;

Fig. 5 Voltammetry diagram investigating a pure cobalt electrode: (a) first cycle, (b) fourth cycle; note the missing peaks in (b).

Fig. 6 Cobalt depth profile as a result of cobalt ion implantation and deposition (MePIIID) into nickel electrodes (Monte Carlo simulation with a total dose of $2 \times 10^{16}$ ions $/ \mathrm{cm}^{2}$, ion energy $3.8 \mathrm{keV}$ at $50 \%$ pulse bias duty cycle). 

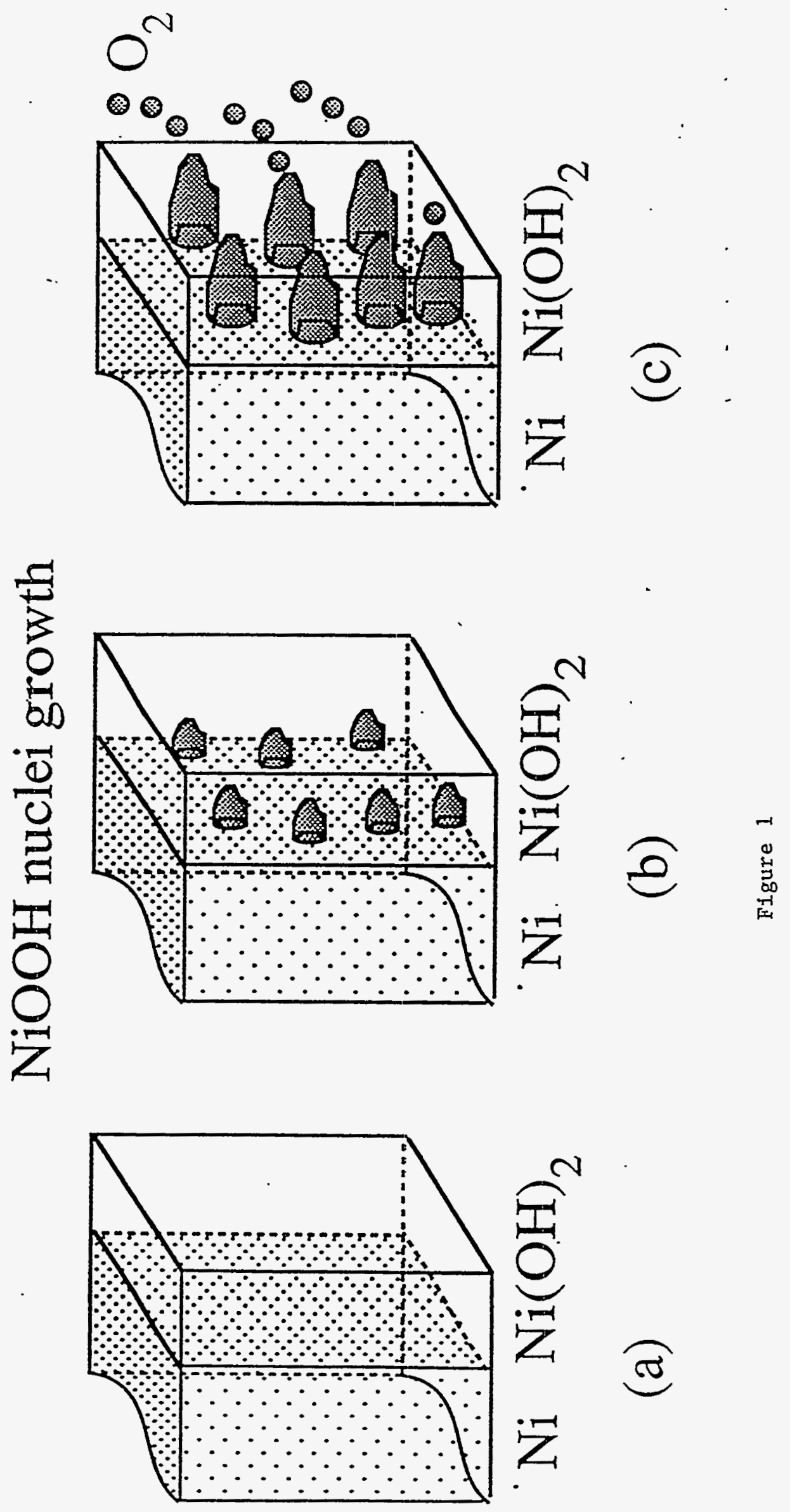


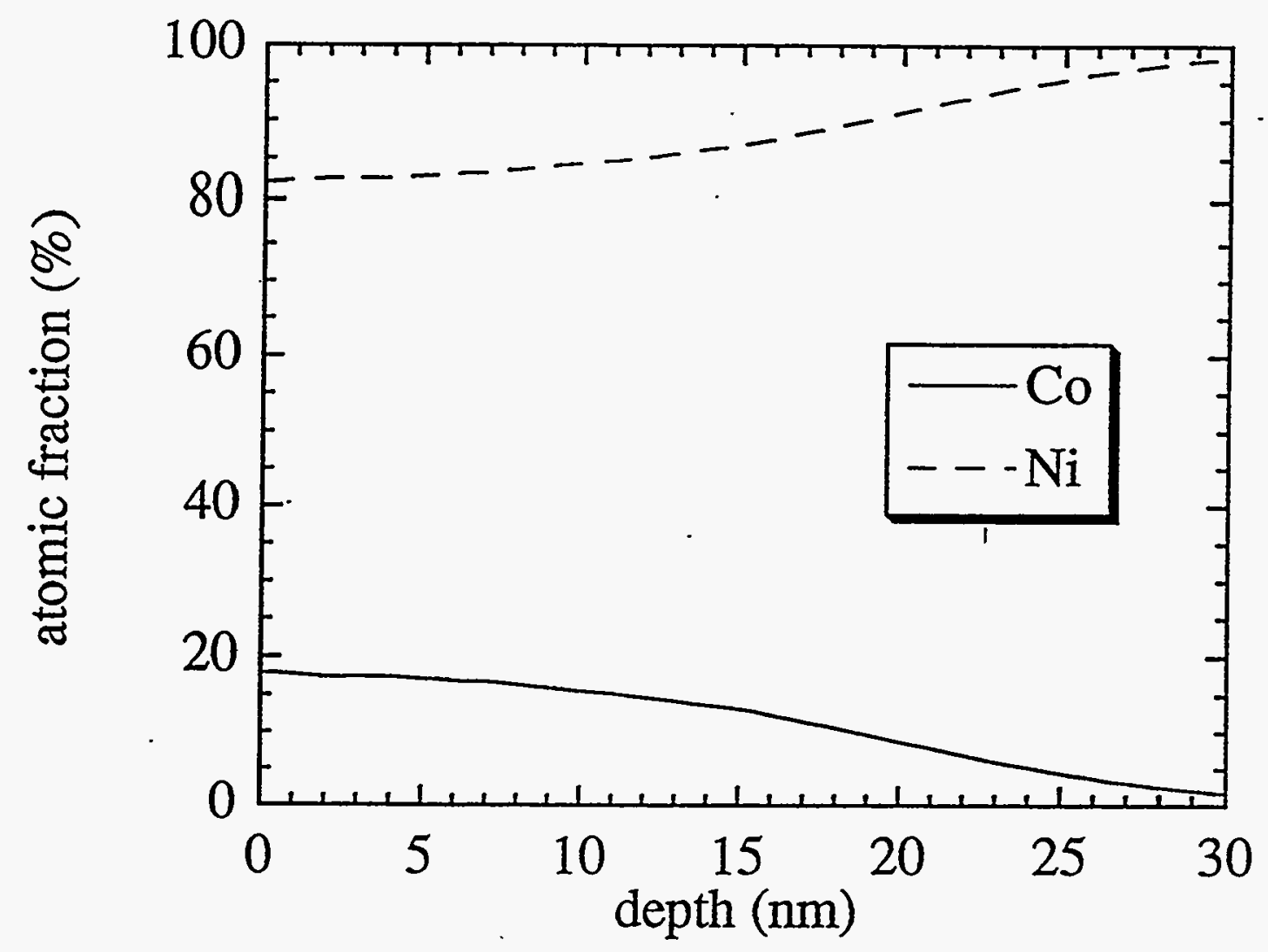

Figure 2 


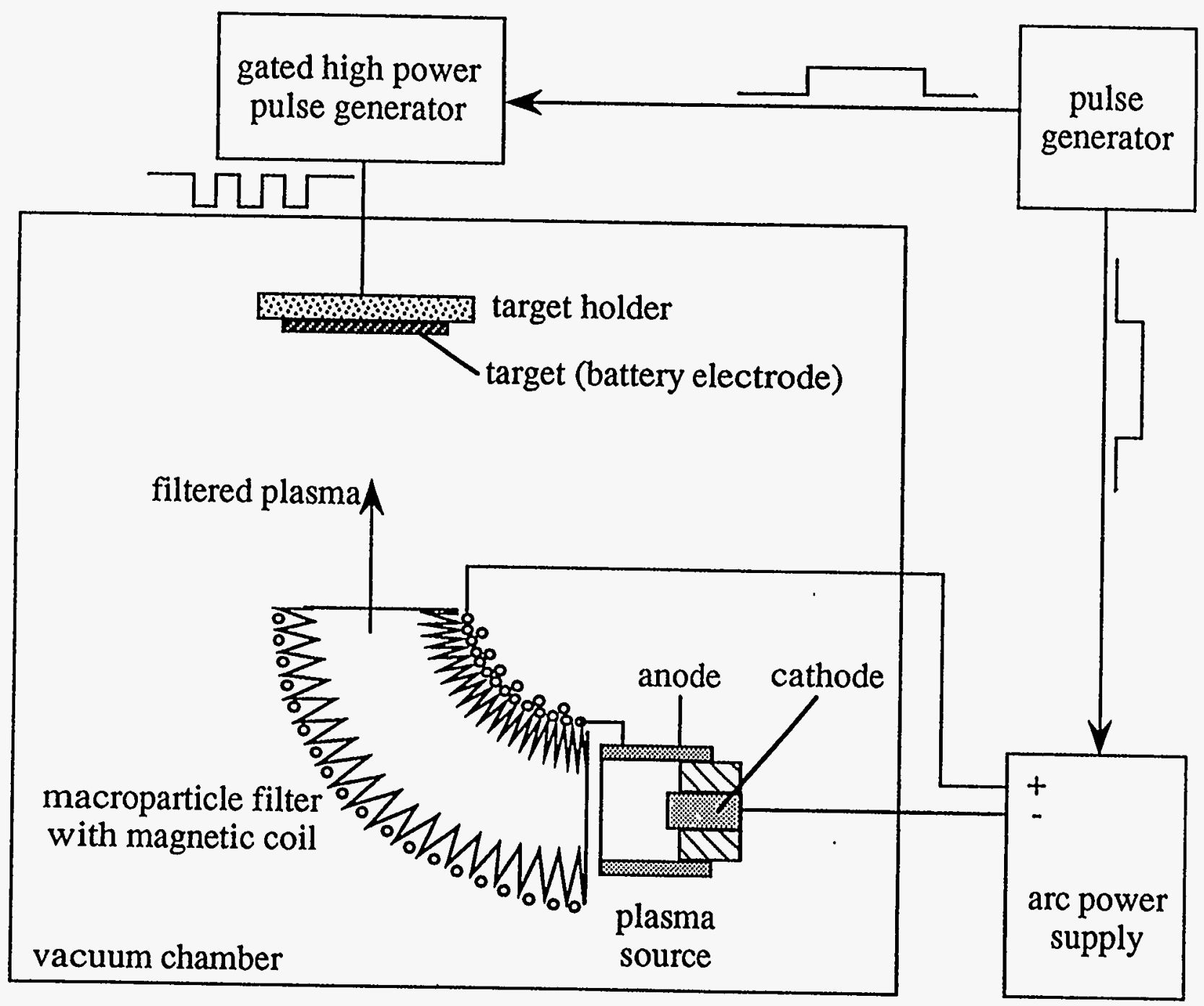

Figure 3 


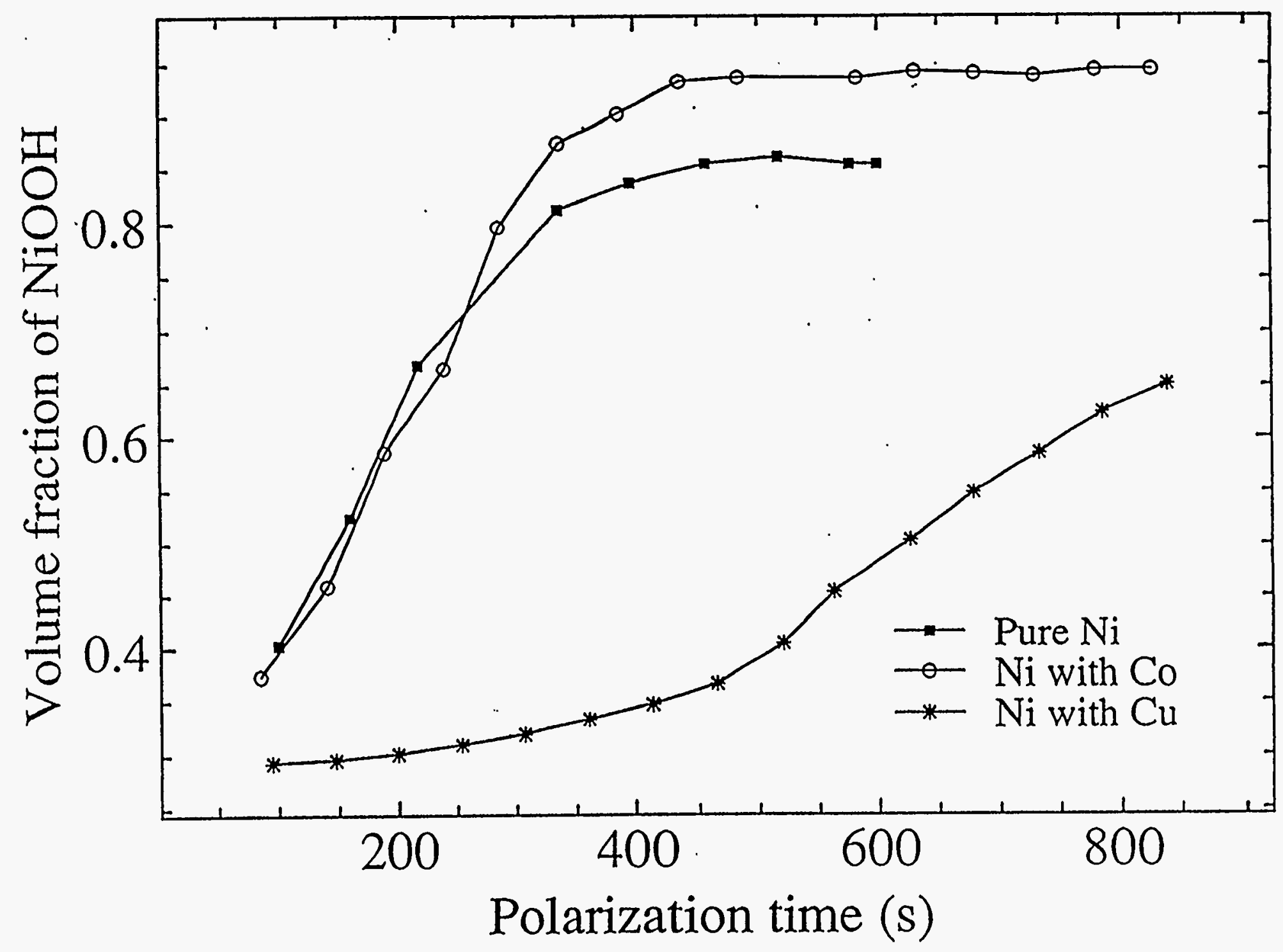

Figure 4 

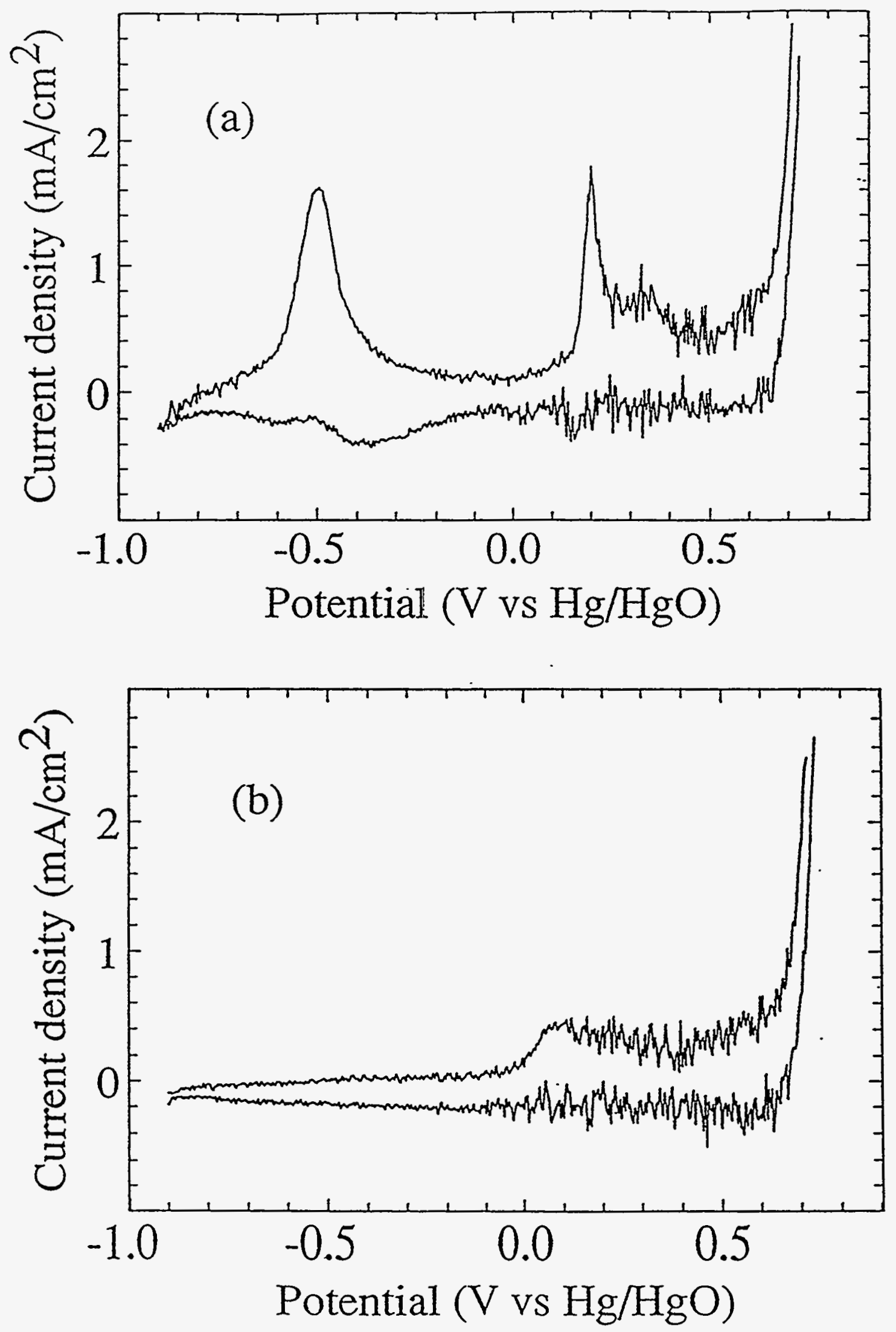

Figure 5 


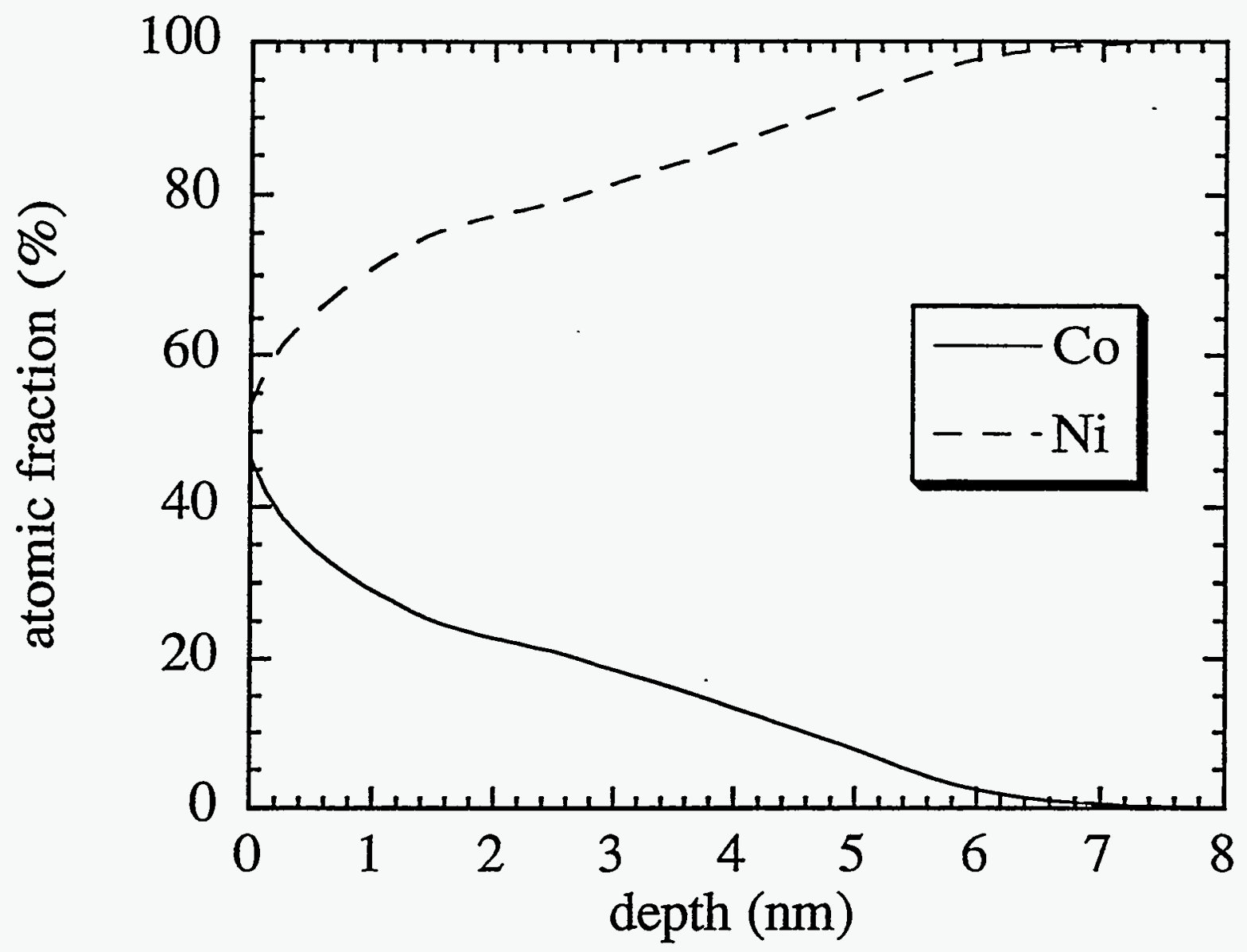

Figure 6 